\title{
Psicoterapia transcultural da migração ${ }^{1}$
}

\author{
Marie Rose Moro* \\ Universidade Paris Descartes, Hospital Avicenne. Bobigny, France
}

Resumo: $\mathrm{O}$ tratamento psicológico em situação transcultural nos mostra algumas questões específicas. Neste artigo propomos construir as bases da clínica transcultural com sujeitos imigrantes, expondo os principais elementos necessários à adaptação do enquadramento terapêutico, bem como os princípios, indicações e as limitações da consulta clínica transcultural.

Palavras-chave: clínica transcultural, migração, psicoterapia, famílias migrantes.

\section{Introdução}

A relação terapêutica, ou seja, aquela que o terapeuta busca estabelecer no encontro com seu paciente, é uma relação complexa. A abertura do campo psicoterápico e a inclusão de outros campos de pesquisa permitiram transformar e enriquecer o campo da relação clínica. Da mesma forma, as contribuições das ciências da linguagem, da Antropologia, das psicoterapias, permitiram a construção de uma clínica composta também por novos componentes externos ao dispositivo clássico. No que concerne à Psicoterapia com sujeitos migrantes, que vêm de diferentes países do mundo e falam línguas diversas, quando os pressupostos culturais não são necessariamente compartilhados entre terapeuta e paciente, faz-se necessário uma complexificação do dispositivo clínico, que leve em conta a alteridade presente na dimensão transcultural da relação terapêutica.

\section{Pensando a diferença}

Conforme apontado por Roheim (1943/1972), não existe homem fora da cultura. De acordo com o autor, cultura significa humanidade, e mesmo as manifestações mais elementares da existência humana podem ser consideradas como pontos iniciais da cultura. Portanto, a ideia de um homem em estado natural, universal, cuja existência se daria fora da cultura, corresponde a uma hipótese já bastante recusada.

Já a tradição filosófica define a cultura como uma espécie de corte racional que nos permite apreender o mundo. Toda cultura possui uma série de categorias que permitem aos sujeitos construírem sua leitura própria do mundo e seu modo de atribuir sentido aos acontecimentos. Essas categorias, arbitrárias na medida que variam de uma cultura a outra, podem ser consideradas como sistemas de inteligibilidade transmitidos aos sujeitos de modo implícito. "Se

\footnotetext{
1 Artigo inédito traduzido do original por Viviani do Carmo Huerta, pesquisadora pós-doutoranda em Psicologia Clínica, USP/FAPESP.

* Autor correspondente: marie-rose.moro@cch.aphp.fr
}

representar", segundo a tradição fenomenológica, significa "esculpir no real", ou seja, escolher categorias comuns para perceber o mundo de maneira ordenada. Esses mundos compartilhados são fundamento das representações para cada grupo específico.

Cada sistema cultural engloba uma língua, um sistema de parentesco, um corpo de técnicas e modos de fazer, a culinária, as artes, as técnicas de cuidado, as técnicas de maternagem etc. Todos esses elementos esparsos são estruturados, de maneira coerente, em representações e enunciados linguísticos que atribuem sentido a todos esses aspectos, codificando-os em uma linguagem. Essas representações culturais são a interface entre o mundo individual e o coletivo. São resultado da apropriação feita pelo sujeito dos sistemas de pensamento de origem cultural, garantindo sentido à experiência subjetiva e sua enunciação. $\mathrm{O}$ sujeito incorpora essas representações e se reapropria de suas significações, seus conflitos, seus sentidos. Então, o que seria a cultura do ponto de vista do sujeito?

A cultura é o que permite decodificar "o total" das experiências vividas pelos sujeitos. É o que torna possível antecipar o sentido do acontecimento, logo é o que permite "dominar" a violência do imprevisível, e consequentemente do não sentido. O campo da cultura coloca a disposição do sujeito uma grade de leitura do mundo. Esta decodificação é um processo constituído de ingredientes complexos, de inferências ontológicas (a natureza dos seres e das coisas), mas também inferências de causalidade permitindo atribuir sentido a um acontecimento específico. No interior desses sistemas culturais extremamente complexos e sempre em movimento, devem-se identificar alguns elementos eficazes para compreender e tratar o sofrimento psíquico em situações transculturais (Sindzingre, 1989). Esse é um ponto que buscamos em nossa clínica.

\section{O enigma da doença}

O aparecimento da doença, a incapacidade de cuidar dos filhos, a perda de um parente próximo etc. podem ser desestabilizadores, razões de grande sofrimento para 
os sujeitos migrantes. É o que procuramos atenuar ao buscarmos um sentido possível, mesmo que transitório, junto com o paciente. Todas as sociedades tentam pensar o não sentido. Zempléni (1985) aponta a necessidade de se definir as teorias etiológicas, ou seja, as teorias culturais sobre as quais cada um se apoia para sobreviver à dor e ao não sentido. Assim, iremos levar em conta, no discurso dos pacientes, a participação de imagens culturais: divindades, entidades da água, da terra etc. Esses enunciados antes de serem tomados em seu conteúdo, devem ser pensados enquanto processos. São constituídos por um corpo organizado de hipóteses das quais o sujeito se apropria, mesmo que apenas em parte, em um momento preciso de sua vida, quando se faz necessário e sempre de maneira parcial.

Essas hipóteses são colocadas à disposição do sujeito pelo grupo, que lhes transmite de múltiplas formas: pela experiência, pelo discurso, por enunciados não linguageiros, tais como rituais, pelas técnicas do corpo, pelas técnicas do cuidado, por jogos etc. Esses são mecanismos de produção de sentido grupal, familiar e individual, logo muito variáveis e modificáveis com o tempo. As teorias etiológicas são em si, "formas vazias", suficientemente gerais e implícitas para serem tomadas, de modo singular, por todos os indivíduos do mesmo grupo cultural, em um determinado momento. Essas teorias etiológicas que utilizam modalidades culturais de dizer e de compreender o mundo são encarnadas em enunciados correntes, pois inscritos na cultura, e, em nenhum momento, devem ser entendidos como material delirante, mesmo se não compartilhamos seu sentido. Esta confusão é muitas vezes origem de vários mal-entendidos de interpretação e de diagnóstico. Desta forma quando o paciente justifica uma mudança de humor por um ataque de bruxaria, não se trata de delírio ou de uma negação, mas talvez seja seu modo de elaborar, dar sentido e modificar essa alteração que lhe concerne. Levar em conta a dimensão cultural da elaboração permite diferenciar essas inúmeras possibilidades de atribuir sentido em face de um mesmo enunciado.

Enfim, toda teoria etiológica enunciada implica a necessidade de uma técnica de tratamento particular. Toda teoria etiológica contém nela mesma, uma forma, uma palavra e um ato. A função dinâmica das teorias etiológicas é a de revelar o sentido da causa do "mal", e isso impõe ao paciente um ato correspondente a ser feito. A eficácia defensiva para o sujeito está no próprio "ato", e para o grupo, para as famílias está em suas consequências, e não no conteúdo do próprio enunciado. Essas teorias articuladas aos atos mobilizam as afiliações, ou seja, as instâncias de pertencimento do sujeito que padece; essas modificações, e todos os relatos que daí decorrem, reorientam o lugar do indivíduo em uma trama familiar e no grupo. Mais além, também permitem a emergência de uma nova trama de enunciados e de uma nova forma de elaboração dos conflitos intersubjetivos e psíquicos. A escola de Dakar, em torno do psiquiatra Henri Collomb e de antropólogos como András Zempléni, por exemplo, insistia na presença dos processos persecutórios nas teorias etiológicas, pensando-os como capazes de mobilizar o grupo em torno do paciente. Sabe-se que os conteúdos persecutórios trazidos pelos pacientes causam inúmeros mal-entendidos de interpretação. Muitas vezes são tomados como um modo de negação do sofrimento, ou como delírio paranoico individual, enquanto na verdade, tratam de uma tentativa de mobilizar as afiliações do paciente, graças a um mecanismo que desculpabiliza individualmente o sujeito, para focar sobre um sistema amplo de interações coletivas.

A cultura deve ser tomada como um conjunto dinâmico de representações móveis em contínua transformação, um sistema aberto e coerente com o qual o sujeito está em constante interação. A esta dimensão de pertencimento cultural, devemos associar a dinâmica do evento migratório, suas consequências potencialmente traumáticas, e também, os modos de aculturação secundária a esta migração e as vicissitudes de toda inscrição em uma nova sociedade e em uma nova língua.

\section{Trauma eventual e potencialidade migratória}

$\mathrm{O}$ acontecimento migratório não é apenas um ato social, mas também psíquico. Devemos insistir sobre este aspecto, pois é fundamental para a clínica com o sujeito migrante. $\mathrm{O}$ deslocamento migratório implica ruptura do contexto externo que o cerca, o que "implica" uma desorganização do universo do sentido cultural interiorizado pelo paciente. A migração é um acontecimento sociológico, inscrito em um contexto histórico e político que não é sem consequências para os sujeitos. As razões que levam ao deslocamento migratório são diversas, nos contextos políticos, econômicos, ambientais e familiares. Sabemos que à experiência migratória se somam as condições que precederam a viagem. Os sujeitos que buscam refúgio político podem ter sido submetidos à tortura e a enormes violências no país de origem, podem carregar um passado traumático pré-migratório que irá modificar o modo de viverem o exílio. Em todos os casos, toda migração é um ato de coragem que engaja a vida dos indivíduos e resignifica toda a história familiar dos sujeitos, inclusive por várias gerações. Este ato de coragem é vivido pelos indivíduos de forma ambivalente: desejo de partir e medo de abandonar a família, desejo de independência e de manter os laços, modo de resolução de conflitos familiares e efetivação de uma trajetória de ruptura ou de aculturação no interior de seu próprio país etc. A migração, aí está sua grandeza existencial, é um ato complexo que não pode ser reduzido às categorias do acaso ou da necessidade.

No entanto, quais sejam as motivações deste ato, a migração pode ser traumática. $\mathrm{O}$ traumatismo migratório não é constante, nem tampouco inelutável. Fatores sociais desfavoráveis (no país de origem ou no país de destino) serão fatores agravantes para a irrupção do traumático. Muitas vezes, alguns sinais irão aparecer apenas après-coup. Quando advém, esse traumatismo não leva necessariamente a efeitos sintomáticos, pode ser, como 
todo trauma, estruturante e inaugurar uma nova dinâmica subjetiva para o sujeito e abrir para uma nova criatividade. Desta forma, é importante identificar os fatores que apontam a emergência dos riscos transculturais. A hospitalidade, ou seu contrário, a exclusão, a discriminação, o racismo tornam mais frágil esta inscrição na nova sociedade, que é tomada como de acolhida, mas que pode acabar vulnerabilizando ainda mais os sujeitos migrantes.

\section{Os períodos de vulnerabilidade e os riscos do diagnóstico}

Diversos fatores influenciam o modo como as famílias vivem o exílio, tais como a brutalidade da partida, o acolhimento da comunidade de origem. A viagem não engaja apenas aqueles que a fizeram, mas também todos os que irão nascer em terra estrangeira. Spinoza (1670/1999), em Traité théologico-politique, falava do exílio como uma triste alegria.

As pesquisas atuais sobre saúde mental e imigração (Baubet \& Moro, 2013) encontram momentos de vulnerabilidade específica que diferem entre homens e mulheres. No caso das mulheres migrantes, a gravidez e o período de construção das primeiras interações precoces mãe-bebê constituem o primeiro momento de vulnerabilidade. No caso dos homens migrantes, a vulnerabilidade constatada aparece, sobretudo, no período que seus filhos passam pela adolescência, uma vez que estes irão fazer suas escolhas identitárias, mas também irão se afiliar ou desafiliar totalmente do país de origem familiar. Neste momento, o pai se questiona sobre a escolha do seu próprio projeto migratório e de sua capacidade de estruturação. Será em função da integração social e profissional dos filhos que os pais poderão validar, ou se culpabilizar pela escolha de um projeto migratório.

Por outro aspecto, a migração, pelo fato de estar distante, impossibilitando de participar dos rituais e dos acontecimentos familiares e coletivos, dificulta, tanto para homens quanto para mulheres, o atravessamento do luto (Baubet \& Moro, 2013). Nessas situações, o luto pode ser agravado pelo acontecimento migratório e vir a funcionar como um après-coup desta viagem, fazendo emergir novamente suas condições e as relações que puderam ser mantidas ou não com o parente falecido e com o país deixado. Do mesmo modo, quando acontecem eventos traumáticos individuais ou coletivos na terra de exílio, acaba sendo muito complicado se reconstruir, uma vez que o grupo social está ausente para acolher o sofrimento do sujeito e para fornecer os elementos culturais que garantem a significação do vivido em uma trama de sentido (Devereux, 1967/1980). Neste sentido, o indivíduo conta somente com suas defesas individuais e com sua própria resiliência; deverá tentar se apropriar de certas defesas culturais presentes na sociedade de acolhida, o que nem sempre é possível por razões linguísticas, culturais e sociais.

Como dissemos, os acontecimentos traumáticos podem ser potencializados pelas características da situação do exílio (distância, desaparecimento da capacidade de contenção própria ao grupo social). Na situação de exílio, os referentes culturais do sujeito migrante, seus modos de cuidar e de tratar são, muitas vezes, desqualificados pela sociedade de acolhida. Em face do sofrimento, o sujeito migrante dispõe apenas de seus próprios recursos, mas a solidão elaborativa, relacionada às dificuldades linguísticas, sociais e culturais, mina sua capacidade de defesa. Diremos que os acontecimentos mais comuns que contribuem para a vulnerabilidade dos sujeitos migrantes, e que podem potencializar a irrupção do traumático no exilio são: a doença grave de um filho; no caso específico das mulheres, os partos particularmente difíceis; no caso dos homens, os acidentes de trabalho que limitam a vida ativa e profissional (Moro, 2010). Esses episódios podem potencializar a irrupção do traumático e reativar vivências dolorosas do exílio. Por isso, afirmamos a importância de levarmos em conta esses efeitos de potencialização para melhor prevenir e tratar o sujeito migrante, remetendo o acontecimento traumático ao seu contexto, situando-o na trajetória do sujeito (Sturm, Baubet, \& Moro, 2010).

Mas, de que modo esses elementos culturais e o acontecimento migratório atravessam nossa clínica e os modos de tratar os migrantes no país de acolhida?

\section{Repensar o tratamento: complementarismo, descentragem e universalidade psíquica}

No intuito de levar em conta a dimensão clínica, antropológica e também linguística, foi necessário pensar métodos de intervenção que permitam operacionalizar as interações entre o nível coletivo, intersubjetivo e intrapsíquico. Esta questão metodológica foi colocada de maneira rigorosa pelo psicanalista e antropólogo Georges Devereux (1970) enquanto trabalhava na Menninger Clinic nos Estados Unidos. Para Devereux, fundador da etnopsicanálise, seria vão integrar à força certos fenômenos ao campo da Psicanálise ou da Antropologia. A especificidade destes dados reside exatamente no fato de que, para uma boa leitura destes fenômenos, seria necessário o uso obrigatório dessa dupla matriz epistemológica, mas não simultâneo (Devereux, 1972). Tal autor define assim o complementarismo que implica, ao menos, uma dupla leitura de cada relato do paciente, o que contribui ao descentramento do analista, sendo este, o segundo princípio metodológico por ele enunciado para se obter uma leitura transcultural do caso. Uma leitura plural favoreceria a multiplicidade de referências, logo a uma ruptura com a posição etnocêntrica do analista. Seria um modo de lutar contra certa tendência das disciplinas das Ciências Humanas a buscarem sempre uma explicação para o desconhecido no campo do conhecido, indo do diferente ao mesmo, ou seja, às nossas próprias referências (a um mesmo campo epistemológico ou a uma clínica etnocêntrica). Complementarismo e descentragem são os componentes essenciais dessa clínica plural que é a clínica transcultural. 
No plano teórico, o postulado da universalidade psíquica é um pilar central desta clínica, sem o qual a etnopsicanálise não poderia ter se construído, decorrendo a necessidade de dar o mesmo estatuto ético, mas também científico, a todos os indivíduos, a suas produções culturais e psíquicas, as suas diversas maneiras de viver e de pensar, mesmo quando estas podem nos parecer desconcertantes. Todo homem pertence a uma cultura e é imerso nesta referência que constrói sua humanidade e sua universalidade (Nathan, 1986). Trabalhar sobre o particular, sem especular sobre o universal, é uma das bases da abordagem etnopsicanalítica ou de uma psiquiatria transcultural.

Devereux foi o primeiro a construir sua teoria adotando o princípio do complementarismo como base. A partir de seus trabalhos, múltiplas variantes foram criadas, algumas até controversas (Nathan, Moro, na França; Overbeck, na Suíça; Pierre, na Bélgica; ou ainda Rousseau, no Canadá). Mesmo se a base complementarista ainda está em construção, alguns princípios desta clínica já estão bem estabelecidos: a importância da língua materna do paciente, e sobretudo, a passagem de uma língua a outra, a necessidade de se levar em conta as representações culturais do paciente, a presença de um grupo de terapeutas em certas situações etc. Trata-se de um dispositivo de geometria variável, que propõe ora um acompanhamento individual, ora em grupo de coterapeutas. Analisemos alguns parâmetros importantes do dispositivo chamado clínico transcultural (Moro, 1998).

\section{Um dispositivo transcultural de geometria variável}

Iremos descrever o dispositivo das consultas clínicas, colocado em prática em 1985 no Hospital Avicenne, em Bobigny, periferia norte de Paris, destinado às crianças migrantes e suas famílias, o qual desenvolvemos ainda, desde 2008, na Maison des adolescents do Hospital Cochin. Nestas consultas, trabalho com uma equipe de coterapeutas (médicos psiquiatras, psicólogos, enfermeiros, assistentes sociais etc.), todos de origens culturais e linguísticas diversas, sendo grande parte deles formados em Psicologia e Psicanálise e iniciados em Antropologia, Linguística e História. Cada um desses coterapeutas desenvolve uma especialidade diferente e todos se formam na clínica transcultural. Ter vivido a experiência da migração, não é suficiente, nem uma condição necessária para ser um clínico transcultural. O que importa é ter sofrido a experiência de descentramento e de estar familiarizado com sistemas culturais diferentes. Esse grupo permite que as experiências de uns e de outros se potencializem. Buscam-se nas consultas aprendizagem e prática pessoal da alteridade e da mestiçagem, por exemplo, um paciente kabile não será atendido por um terapeuta kabile. O dispositivo proposto é, em sua essência, mestiço e centrado na noção de alteridade (reconhecer as diferenças e valorizá-las no acesso ao tratamento e na técnica utilizada).

\section{Tratar de maneira plural}

Recebemos a maioria das crianças migrantes e suas famílias, em consultas individuais, com a ajuda de um tradutor, quando necessário, e em certos casos, contamos com a ajuda de um grupo de coterapeutas. Mesmo se este dispositivo grupal é utilizado apenas em uma minoria dos casos, será este que iremos descrever, uma vez que é o mais específico, o que nos permite novas abordagens e o que suscita o maior número de interrogações por ser o mais distante da prática clínica habitual.

Este dispositivo é constituído por um número de terapeutas que recebem o paciente e sua família (em geral, uma dezena de coterapeutas, ou ainda, podemos optar por pequenos grupos de três a quatro terapeutas). Nas sociedades tradicionais, o indivíduo é pensado em uma interação constante com seu grupo de pertencimento. Daí decorre a importância do grupo nas situações de tratamento de saúde. Além disso, a doença é considerada como um acontecimento que diz respeito não apenas ao sujeito doente, mas também à família materna e paterna do paciente e ao grupo ao qual pertence (cultural, clã, religião, confraria etc.). O sujeito, consequentemente, é acolhido em um dispositivo grupal ao menos em algum momento do tratamento, ou pelo grupo social, familiar, ou por um grupo terapêutico. $\mathrm{O}$ tratamento coletivo da doença permite fazer um compromisso entre uma etiologia coletiva e familiar do mal, que aflige o paciente, e uma etiologia individual.

Os profissionais externos, que nos encaminharam a família, participam das consultas ao menos nos primeiros encontros, uma vez que carregam também um "pedaço" da história daquela família. Esta presença ativa evita que a chegada da família na consulta transcultural seja tomada como uma nova ruptura no seu longo e caótico caminho ao acesso ao tratamento. Além da função de representar uma modalidade cultural de troca, uma possibilidade de coconstrução de um novo sentido cultural, lugar de ancoragem do paciente, o grupo permite uma materialização da alteridade, uma vez que cada terapeuta possui uma origem cultural diferente, e uma transformação desta alteridade em instrumento terapêutico. De acordo com Devereux (1972), a alteridade passa a ser suporte da elaboração psíquica: a mestiçagem de homens e mulheres, de teorias, de maneiras de fazer é um fator implícito ao dispositivo. Outro aspecto importante, qual seja o sintoma e a demanda do paciente e sua idade, é que a família é convidada a estar presente nas consultas, uma vez que ela carrega uma parte do sentido do sofrimento do sujeito.

\section{$A$ viagem das línguas}

Para explorar esse processo com precisão, na sua complexidade e riqueza, a língua materna dos pacientes deve estar necessariamente presente nas consultas se ele assim a solicita. O paciente tem a possibilidade de falar a(s) sua(s) língua(s) materna(s), e, se é este o caso, um coterapeuta ou um intérprete cultural lhe traduz. O procedimento eficiente é a possibilidade de passar de uma língua a 
outra, não a imposição da presença de uma língua materna "fossilizada". De acordo com a vontade, a possibilidade e a natureza do relato, o paciente utiliza esta possibilidade de passar ou não por sua língua materna. Neste texto, o que buscamos é a construção de laço entre as diversas línguas do paciente: de uma língua a outra, de uma cultura a outra.

Desta forma, o "conhecimento cultural compartilhado" permite que o paciente se exprima através de recursos de linguagem, de mal-entendidos, subentendidos e significações implícitas, o que é fundamental quando o sujeito aborda temas difíceis - a sexualidade, as relações íntimas entre homens e mulheres, entre pais e filhos, mas também, a religião, o sagrado, os sonhos. O caso de certos pacientes de culturas, por exemplo, em que os sonhos são sagrados, em que a realidade onírica se impõe à realidade diurna. $\mathrm{O}$ que acontece quando não dispomos de um intérprete transcultural ou quando os coterapeutas não são formados na clínica transcultural? Devemos tentar adotar uma postura transcultural, ou seja, privilegiar uma posição emic, que vai permitir ao paciente nos contar o sentido do seu sofrimento. Devemos tentar alcançar o ponto de vista do paciente do interior de sua cultura, e não adotar uma postura etic, na qual imporíamos nosso ponto de vista externo à cultura do paciente.

É importante pensarmos que trabalhamos sobre um discurso traduzido e não diretamente enunciado (paciente/ terapeuta/paciente), logo um discurso que tem como mediação um tradutor, o que implica incluí-lo no dispositivo terapêutico e formá-lo na situação clínica transcultural. Uma formação é necessária, bem como sua participação na supervisão clínica, para que possa retomar as situações relacionais e linguísticas que lhe colocam problemáticas. A tradução não é simplesmente um recurso, mas participação no processo interativo da psicoterapia em situação transcultural.

\section{A contratransferência cultural}

Em tal dispositivo, é necessário instaurar, além dos dispositivos convencionais de análise da transferência e da contratransferência, uma modalidade específica de trabalho relacionado a contratransferência cultural. Esta é uma das razões de privilegiarmos o dispositivo grupal, pois ao fim de cada atendimento, o grupo se esforça para explicitar a contratransferência de cada um dos terapeutas em uma discussão dos afetos sentidos por cada um, os implícitos, as teorias etc., que conduziram cada um a pensar, a fazer inferências e a formular cada uma das intervenções durante $o$ atendimento.

Sabemos que a dinâmica da transferência e da contratransferência foi uma verdadeira revolução clínica operada por Freud. Desde a elaboração do modelo clássico da cura, a palavra do sujeito é colocada como ato da terapêutica, seu suporte sendo o laço entre o psicanalista e o paciente, ou seja, a transferência (Freud, 1910-1970). A transferência designa o processo pelo qual o desejo inconsciente do sujeito se atualiza na cena analítica montada entre o psicanalista e seu paciente. No sentido inverso, a contratransferência do pesquisador é a soma de todas as reações do clínico em relação a seu paciente ou a seu objeto de pesquisa. A contratransferência cultural é o modo que o terapeuta se posiciona em relação à alteridade do paciente, a seus modos de fazer, de pensar culturalmente a doença etc., por exemplo, um paciente soninké sofre de insônia, mas logo que consegue adormecer, tem sonhos funestos. Ele vai consultar um curandeiro soninké que lhe diz que ele havia sido atacado por um espírito de um ancestral descontente. O curandeiro, o sábio, aquele que sabe interpretar os sonhos lhe pede que faça um sacrifício. Qual é a minha posição interna em face deste relato e, sobretudo, perante o ato proposto pelo curandeiro que se opõe a minha intervenção, terapêutica ou medicamentosa?

Desta posição contratransferencial decorre minha resposta ao paciente. A transferência e a contratransferência cultural são alimentadas pela história, pela política, pela geografia entre outras. O paciente e o terapeuta estão inscritos em uma história coletiva que imprime suas marcas em suas reações conscientes e inconscientes. Sem uma análise desta contratransferência cultural, corremos o risco de reações agressivas, afetivas, ou mesmo racistas (Mac Dougall, 1978). Descentragem e análise da contratransferência cultural são, sem dúvida, os dois mecanismos mais difíceis da prática transcultural e os instrumentos mais preciosos para construir um lugar suficientemente bom do terapeuta, que não seja obscurecido pela diferença cultural.

Assim, este dispositivo clínico, que integra a dimensão psíquica e cultural, não é propriamente específico. Seria mais apropriado dizermos que se trata de um enquadramento psicoterápico complexo e mestiço que permite o descentramento do terapeuta e a inclusão da dimensão cultural do paciente migrante. Longe de serem obstáculos, a língua dos pacientes, suas representações culturais, as lógicas culturais, que lhes povoam o imaginário, são considerados elementos da cena terapêutica e fontes de criatividade para os terapeutas e para os pacientes.

\section{Quando propor a abordagem transcultural?}

Quando devemos pensar que um dispositivo clínico que integre a dimensão cultural do paciente é necessário? Um esquema simples: sugerimos o dispositivo transcultural a um paciente, independente de sua idade, ou para famílias migrantes e/ou filhos de migrantes, de duas formas. São eles:

Como primeira intenção, ou seja, como sendo o único dispositivo terapêutico do paciente ou da família. Propomos o dispositivo em primeira intenção, quando a sintomatologia do sujeito aparece como uma consequência direta da migração aos pacientes, cujo sintoma tenha uma codificação cultural, tais como, uma teoria etiológica de bruxaria, possessão etc.; ou quando o sintoma é diretamente codificado em sua própria forma: transe, comunicação com os ancestrais culturais, ou ainda, quando os próprios 
pacientes demandam explicitamente pela descentragem cultural: evocam a necessidade de passar por sua língua materna, de se ocuparem "das coisas do país", por exemplo. Estas indicações concernem tanto a primeira quanto a segunda geração de migrantes. Em todas essas indicações, o dispositivo transcultural é suscetível de funcionar como uma máquina de fabricar laços entre o universo de pertencimento do paciente migrante e o universo da sociedade de acolhida.

Como segunda intenção, que é o tratamento mais frequente em nossas consultas, ou seja, quando o paciente já beneficia de outro espaço de tratamento de tipo clássico. Neste caso, propomos o dispositivo transcultural quando o paciente experimenta uma errância entre os diversos sistemas ocidentais clássicos de tratamento (médicos, psicólogos, psiquiatras) e os modos tradicionais de tratar o sofrimento (curandeiros, etc.), sem poder traçar um laço entre esses dois sistemas discursivos e sem que nenhum destes espaços consiga desencadear um verdadeiro trabalho associativo de elaboração e de transformação. $O$ tratamento em segunda intenção será também proposto aos pacientes migrantes em errância que, após um percurso caótico pelos diversos serviços de saúde, se encontram excluídos de todo e qualquer acompanhamento. E enfim, a todos aqueles que nos dizem não serem escutados pelo sistema convencional, que nos contam uma série de mal-entendidos culturais ou que são desrespeitados em sua singularidade. Esses indivíduos ou famílias, com frequência, abandonam ou recusam toda aproximação terapêutica convencional.

A estas indicações mais recorrentes, devemos incluir uma nova população, os casais mistos que vivenciam a problemática da mestiçagem cultural, as famílias que adotaram no estrangeiro uma criança, os menores isolados que chegam em outro país sozinhos, os refugiados que vivenciaram traumas profundos, as mães migrantes que sentem dificuldades para construir um vínculo parental na situação do exílio. A abordagem transcultural não se aplica a uma patologia específica, mas a uma situação que requer um olhar específico.

Por fim, como toda técnica psicoterápica, ela reconhece seus limites: quando o paciente e sua família resistem ou negam a elaboração da alteridade cultural, no caso de pacientes em ruptura com seu grupo de pertencimento, ou ainda, quando se explicita a necessidade de uma elaboração individual do sofrimento psíquico. Nestes casos, propomos os dispositivos clássicos tradicionais, mesmo sabendo que o manejo dos conteúdos culturais não será realizado individualmente, apenas poderá ser contado pelo paciente.

\section{Conclusão: por uma pragmática da alteridade}

Outros parâmetros da técnica transcultural podem ser integrados em lugares não convencionais em função da personalidade do clínico e de sua desenvoltura com alguns conteúdos enunciados; pode-se modificar a temporalidade das consultas e a regularidade dos encontros e, também, a constituição de pequenos grupos de coterapeutas. No entanto, para produzir todas essas modificações deve-se fazer prova de sua pertinência e eficácia. A importância é de iniciar os encontros com a construção de um sentido cultural que integre as hipóteses dos pacientes.

Não se trata nem de magia, nem de prática "demoníaca", a psicoterapia transcultural, assim com toda técnica psicoterápica, reconhece suas indicações e seus limites que devem estar longe de toda e qualquer paixão ideológica cega. A clínica transcultural não é uma clínica destinada aos experts ou aos viajantes. Ela pertence a todos que se dedicam a uma formação rigorosa e múltipla.

\section{Migration transcultural psychotherapy}

Abstract: The psychological treatment in a transcultural situation shows us some specific issues. In this article we propose to build the foundations of the transcultural clinic with immigrants, exposing the main elements required for adapting the therapeutic framework, as well as the principles, indications and the limitations of the transcultural clinical consultation.

Keywords: transcultural clinic, migration, psychotherapy, migrant families.

\section{Psychothérapie transculturelle des migrants}

Résumé: Le traitement psychologique en situation transculturelle nous montre certaines questions spécifiques. Dans cet article, nous proposons de construire la base de la clinique transculturelle avec des sujets migrants, en exposant les éléments qui se rendent nécessaires à l'adaptation du cadre thérapeutique, ainsi que les principes, indications et les limitations de la consultation transculturelle.

Mots-clés: clinique transculturelle, migration, psychothérapie, familles migrants. 


\section{La psicoterapia transcultural con los inmigrantes}

Resumen: El tratamiento psicológico en situación intercultural pone en discusión diversos temas específicos. En este artículo nos proponemos a construir las bases de temas clínicos transculturales con los inmigrantes, exponiendo los elementos necesarios para adaptar el marco terapéutico y también los principios, indicaciones y limitaciones de la consulta clínica transcultural.

Palabras clave: clínica transcultural, migración, psicoterapia, familias migrantes.

\section{Referências}

Baubet, T., \& Moro, M. R. (2013). Psychopathologie transculturelle. Paris: Masson.

Devereux, G. (1980). De l'angoisse à la méthode. Paris: Flammarion. (Trabalho original publicado em 1967)

Devereux, G. (1970). Essais d'ethnopsychiatrie générale. Paris: Gallimard.

Devereux, G. (1972). Ethnopsychanalyse complémentariste. Paris: Flammarion.

Freud, S. (1970). Perspectives d'avenir de la thérapeutique psychanalytique. In S. Freud, La technique psychanalytique. Paris: PUF. (Trabalho original publicado em 1910)

Moro, M. R. (1998). Psychothérapie transculturelle des enfants et des adolescents. Paris: Dunod.

Moro, M. R. (2010). Nos enfants demain. Pour une société multiculturelle. Paris: Odile Jacob.

Mac Dougall, J. (1978). Plaidoyer pour une certaine anormalité. Paris: Gallimard.

Nathan, T. (1986). La folie des autres. Traité d'ethnopsychiatrie clinique. Paris: Dunod.

Roheim, G. (1972). Origine et fonction de la culture. Paris: Gallimard. (Trabalho original publicado em 1943)
Sindzingre, N. (1989). La notion de transfert de représentations: l'exemple des aspects culturels de l'infortune. Anthropologia medica, 5-6.

Spinoza, B. (1999). Traité théologico-politique. Paris: PUF. (Trabalho original publicado em 1670)

Sturm, G., Baubet, T., \& Moro, M. R. (2010). Culture, trauma and subjectivity: The french ethno-psychoanalitic approach. Traumatology, 16(4), 27-38.

Zempléni, A. (1985). La "maladie" et ses "causes" [Introduction]. L'Ethnographie, 81(2), 13-44.

\section{Sites de referência}

Association Internationale d'Ethnopsychanalyse. www. clinique-transculturelle.org

Revue transculturelle de référence. www.revuelautre.com 